\title{
CT of the medial clavicular epiphysis for forensic age estimation: hands up?
}

\author{
Magdalini Tozakidou $^{1}$ (D) $\cdot$ Rieke L. Meister $^{1} \cdot$ Lennart Well $^{2} \cdot$ Kay U. Petersen ${ }^{3} \cdot$ Sebastian Schindera $^{4} \cdot$ Eilin Jopp-van \\ Well $^{5} \cdot$ Klaus Püschel ${ }^{5} \cdot$ Jochen Herrmann ${ }^{1}$
}

Received: 16 July 2020 / Accepted: 27 January 2021 / Published online: 24 February 2021

(C) The Author(s) 2021

\begin{abstract}
Purpose The aim of this study was to assess the impact of arm position in computed tomography (CT) of the clavicle performed for forensic age estimation on clavicular position, image noise, and radiation dose.

Methods and materials Forty-seven CT scans of the medial clavicular epiphysis performed for forensic age estimation were conducted with either hands and arms held upwards $\left(\mathrm{CT}_{\mathrm{HU}}, 28\right.$ persons) or positioned at the body $\left(\mathrm{CT}_{\mathrm{HD}}, 19\right.$ persons). Presets were identical for both positions ( $70 \mathrm{mAs} / 140 \mathrm{kVp}$; Brilliance iCT, Philips). Each CT scan was reconstructed with an iterative algorithm (i-Dose 4) and evaluated at the middle of the sternoclavicular joint. Clavicular angle was measured on a.p. topograms in relation to a horizontal line. Quantitative image noise was measured in air at the level of medial clavicular epiphysis. Effective dose and scan length were recorded.

Results Hands-up position compared with hands-down position resulted in a lower lateral body diameter $\left(\mathrm{CT}_{\mathrm{HU}} 41.1 \pm 3.6 \mathrm{~cm}\right.$ vs. $\left.\mathrm{CT}_{\mathrm{HD}} 44.6 \pm 3.1 \mathrm{~cm} ; P=0.03\right)$, a reduced quantitative image noise $\left(\mathrm{CT}_{\mathrm{HU}}: 39.5 \pm 9.2 ; \mathrm{CT}_{\mathrm{HD}}: 46.2 \pm 8.3 ; P=0.02\right)$, and lower $\mathrm{CTDI}_{\mathrm{vol}}(5.1 \pm 1.4 \mathrm{mGy}$ vs. $6.7 \pm 1.8 \mathrm{mGy} ; P=0.001)$. Scan length was longer in patients examined with hands up (HU: $8.5 \pm 3.4$ $\mathrm{cm}$; HD: $6.2 \pm 2.1 \mathrm{~cm} ; P=0.006)$. Mean effective dose for $\mathrm{CT}_{\mathrm{HU}}$ was $0.79 \pm 0.32 \mathrm{mSv}$ compared with $0.95 \pm 0.38 \mathrm{mSv}$ in $\mathrm{CT}_{\mathrm{HD}}$ $(P=0.12)$. Clavicular angle was $17^{\circ} \pm 6^{\circ}$ in patients with hands down and $32^{\circ} \pm 7^{\circ}$ in patients with hands up $(P<0.001)$.

Conclusion By elevated arm positioning, the image quality of clavicular CT scans can be improved while maintaining radiation dose compared with hands down. Clavicular position differs according to the hand position. Thus, positioning patients with elevated hands is advisable for forensic clavicular CT examinations, but multiplanar CT reconstructions should be adjusted to clavicular position and scan length should be reduced to a minimum.
\end{abstract}

Keywords Image noise $\cdot \mathrm{CT} \cdot$ Forensic age estimation $\cdot$ Patient positioning

Magdalini Tozakidou

magdalini.tozakidou@gmail.com

1 Section of Pediatric Radiology, Department of Diagnostic and Interventional Radiology and Nuclear Medicine, University Medical Center Hamburg-Eppendorf, Martinistraße 52, 20246 Hamburg, Germany

2 Department of Diagnostic and Interventional Radiology and Nuclear Medicine, University Medical Center Hamburg-Eppendorf, Hamburg, Germany

3 Department of Psychiatry and Psychotherapy, University Hospital Tübingen, Tübingen, Germany

4 Department of Radiology, Cantonal Hospital Aarau, Aarau, Switzerland

5 Department of Forensic Medicine, University Medical Center Hamburg-Eppendorf, Hamburg, Germany

\section{Introduction}

With increasing migration into European countries, forensic age assessment in young adults has become increasingly important [1]. When the chronological age cannot be determined alone by non-medical means, medical imaging may be added to specify an age range [2,3]. Provided that $\mathrm{x}$-ray examinations are legally permitted, the AGFAD (Arbeitsgemeinschaft für Forensische Altersdiagnostik, Study Group on Forensic Age Diagnostics) recommends a steps-wise approach beginning with a conventional $\mathrm{x}$ ray examination of the left hand or the teeth [2]. A computed tomography (CT) of the medial clavicle may be supplemented if a minimal age $>18$ or $>21$ years needs to be clarified [3-5]. Minimizing radiation dose remains an important part of imaging, especially since clavicular CT is 
often performed in young and borderline adults due to the greater risk of malignancy after radiation exposure [6].

Dose reduction strategies may include automatic tube current modulation, different ways of mathematical postprocessing algorithms, such as iterative reconstructions, but also protocol adjustment to patient habitus and proper patient positioning [7-9]. For example, in cervical spine, CT examinations with a low shoulder position allow the application of lower radiation dose with no reduction of image quality [10]. Likewise, in trauma patients, arm-raising for thoracoabdominal CT results in higher image quality and lower radiation dose [7].

To our knowledge, no definite guidelines on patient positioning for forensic clavicular $\mathrm{CT}$ imaging have been published so far. Yet, it is common practice to use an armsdown position in forensic age estimation clavicular $\mathrm{CT}$ protocols because the clavicular shaft better aligns with the standard axial imaging planes. A number of studies recently suggested to use thin-sliced CT with a multiplanar reformation algorithm which would also allow for a more variable arm positioning [11-15].

The aim of this study was to assess the impact of hand position in clavicular CT performed for forensic age estimation on image noise, image reconstruction, and radiation dose.

\section{Materials and methods}

\section{Patients and $\mathrm{CT}$ protocol}

Institutional review board approval was waived for this retrospective investigation. CT examinations during the period 10/ 2017 to 10/2018 from 28 male persons (mean age $20.5 \pm 3.4$ years as reported by the subjects) were included. Results were compared with data from a previously published collective [16], which had been examined with hands positioned next to the body (hands down, $\mathrm{CT}_{\mathrm{HD}}$ ).

A 256-multidetector CT scanner (Brilliance iCT, Philips, the Netherlands) was used to perform unenhanced CT scans of the clavicle. Scan parameters are summarized in Table 1. Subjects were in a supine position and asked to place their hands, arms, and shoulders upwards $\left(\mathrm{CT}_{\mathrm{HU}}\right)$. The anteroposterior (ap) distance and lateral body diameter at the midlevel of the medial clavicular epiphysis was measured in subjects, in which the entire soft tissues were included in the scan. Lateral diameter was available in eight subjects with hands down and in 27 patients with hands up, anteroposterior diameter in 12 subjects with hands down and in 24 subjects with hands up. Scan length was documented in all patients. The clavicular angle was measured on ap topograms in relation to a horizontal line (Fig. 1).

\section{Image noise}

Image noise was measured in air at the midlevel of medial clavicular epiphysis by one pediatric radiologist with 8 years of experience in CT imaging as described earlier [16]. The standard deviation of mean $\mathrm{CT}$ numbers measured in Hounsfield units (HU) within a ROI was documented in three ROIs on each side.

\section{Radiation exposure}

The CT automatically generated the volume CT dose index $\left(\mathrm{CTDI}_{\mathrm{vol}}\right)$ and the dose-length product (DLP). In addition, we calculated a theoretical DLP for a normalized scan length of 5 $\mathrm{cm}$, which was thought to be sufficient for scanning the medial clavicular epiphysis. For estimation of the effective dose the DLP was multiplied by an organ specific conversion coefficient of $0.0137 \mathrm{mSv} / \mathrm{mGycm}$ for an adult chest region at 140 $\mathrm{kVp}$ as described previously $[16,17]$.

\section{Image reconstruction}

Since differences of classifications in axial and coronal reformations and influence of slice thickness have been described $[12,13]$, images were reviewed using multiplanar reformations (MPRs) with slice thickness/increment of $1.0 / 0.5 \mathrm{~mm}$ on a PACS workstation. In order to avoid anatomic distortion due to changes in clavicular position in subjects with hands up, reformations were aligned along the sternum for coronal views and along the clavicular shaft for adapted axial views in all scans (Fig. 2).

\section{Statistical analysis}

To examine possible correlations of scan length and radiation dose, the nonparametric Spearman correlation coefficient has been calculated. For the comparison of image noise between subjects with arms up and subjects with arms down, the mean values of six measurements in each subjects were used and Student's $t$ tests were performed. Statistical tests were performed by using appropriate statistical software (SPSS Statistics, version 25 and GraphPad QuickCalcs). A $P$ value $<0.05$ was considered statistically significant.

\section{Results}

A total of 28 CT scans of the medial clavicles with hands up and $19 \mathrm{CT}$ with hands down were evaluated. The anthropomorphic parameters were available in 23 patients with hands up and in 19 patients with hands down and did not differ between both groups (body weight: HD: $68 \pm 8 \mathrm{~kg}$ vs HU 


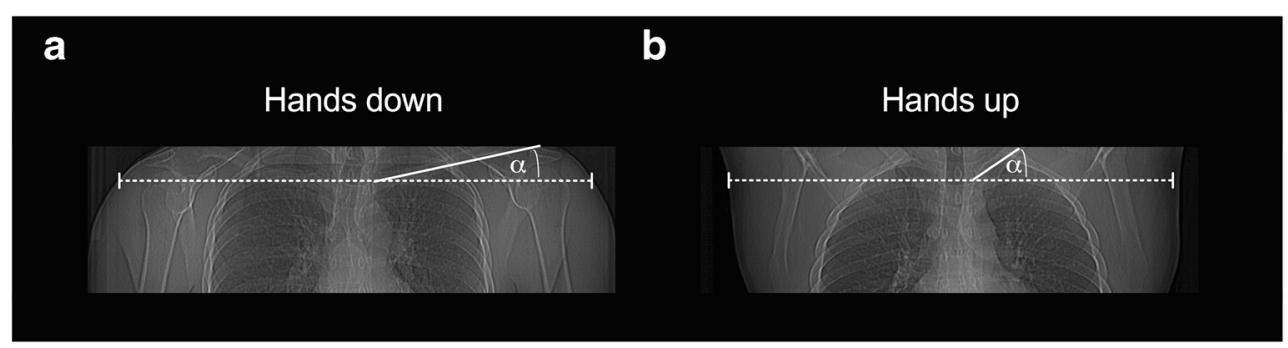

Fig. 1 Coronal topograms of example patients positioned with hands lateral to the thorax (a) and with hands up (b). Lateral diameter was measured at the level of the medial clavicular epiphysis (dotted line).

$68 \pm 8 \mathrm{~kg}, P=0.81$; height: HD $174 \pm 5 \mathrm{~cm}$ vs HU $175 \pm 8 \mathrm{~cm}$; $P=0.65)$.

\section{Body diameter, clavicular angle in relation to arm posture, and multiplanar reformations}

The lateral body diameter was less with hands positioned upward than downward $\left(\mathrm{CT}_{\mathrm{HU}} 41.1 \pm 3.6 \mathrm{~cm}\right.$ vs. $\mathrm{CT}_{\mathrm{HD}} 44.6 \pm$ $3.1 \mathrm{~cm} ; P=0.03)$. The ap diameter was not significantly
Clavicular angle $(\alpha)$ was measured between the line through the medial half of the clavicle and a horizontal line

different between both groups $\left(\mathrm{CT}_{\mathrm{HU}} 14.7 \pm 0.9 \mathrm{~cm}\right.$ vs. $\left.\mathrm{CT}_{\mathrm{HD}} 14.4 \pm 1.4 \mathrm{~cm} ; P=0.38\right)$. The clavicular angle increased significantly with hands positioned upward compared with arms positioned downward (right side, $32^{\circ} \pm 7^{\circ}$ vs, $18^{\circ} \pm 6^{\circ}$; left side, $31^{\circ} \pm 7^{\circ}$ vs. $17^{\circ} \pm 6^{\circ} ; P<0.001$; Fig. 1). Example reformations in patients with hands up and hands down are shown in Fig. 2. While the orientation of adapted axial images in patients with hands down is close to axial images of the thorax, the orientation of adapted axial images in patients with
Fig. 2 Systematic reformations of the medial clavicular epiphysis reconstructed with iDose 4 using bone convolution kernel (window level/width, 500/2500). Starting from axial planes $(\mathbf{a}, \mathbf{b})$ and sagittal reformations were performed $(\mathbf{c}, \mathbf{d})$. Coronal images were aligned along the sternum $(\mathbf{e}, \mathbf{f})$. On coronal images, each clavicle was reformatted along the clavicular shaft separately for each side, resulting in adapted axial slices. Example reformations of the right side are shown in $\mathbf{g}$ and $\mathbf{h}$

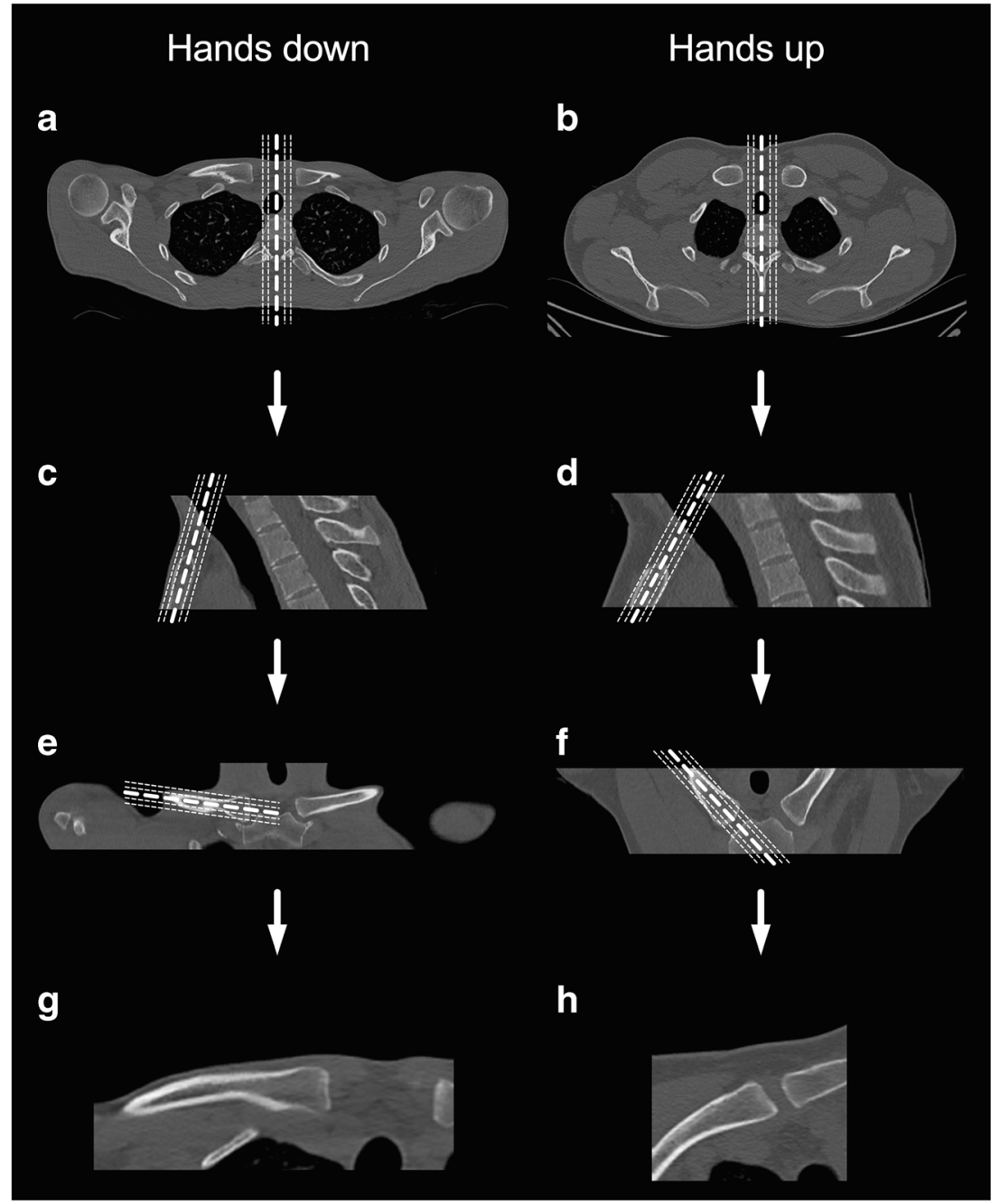


Table 1 Scan and reconstruction parameters

\begin{tabular}{ll}
\hline Parameter & Value \\
\hline Tube voltage [cm] & $140 \mathrm{kVp}$ \\
Reference tube-current-time product & $70 \mathrm{mAs}$ \\
Rotation time & $0.5 \mathrm{sec}$ \\
Pitch factor & 0.579 \\
Detector configuration & $64 \times 0.625 \mathrm{~mm}$ \\
Automatic tube-current modulation & Z-Dom (Philips Healthcare) \\
Image reconstruction algorithm & iDose 4 (Philips Healthcare), bone convolution kernel [18] * \\
Window level/width & $500 / 2500$ \\
Section thickness/increment & $1.0 / 0.5 \mathrm{~mm}$ \\
Field-of-view & $15 \times 15 \mathrm{~cm}$ to $20 \times 20 \mathrm{~cm}$, depending on the person's constitution \\
\end{tabular}

hands up differs according the increased clavicular angle (Figs. 1 and 2).

\section{Image quality and noise}

The subjective image quality was diagnostic in all examinations. Quantitative measurements were performed in the bone window and displayed lower image noise in subjects with hands up than in those with hands down (HU: $39.5 \pm 9.2$; HD: $46.2 \pm 8.3 ; P=0.02$; Fig. 3a).

\section{Radiation exposure}

Upward hand position compared with downward hand position resulted in a lower mean effective tube current time product $(48.8 \pm 12.2 \mathrm{mAs}$ vs. $65.1 \pm 17.9 \mathrm{mAs} ; P=0.001$; Fig. $3 b)$ and a lower mean $\mathrm{CTDI}_{\mathrm{vol}}(5.1 \pm 1.4 \mathrm{mGy}$ vs. 6.7 $\pm 1.8 \mathrm{mGy} ; P=0.001$; Fig. $3 \mathrm{c}$ ). As the mean effective scan length was slightly longer for the hands up than for the hands down position $(8.5 \pm 3.4 \mathrm{~cm}$ vs. $6.2 \pm 2.1 \mathrm{~cm}, P=$ 0.006; Fig. 3d, no significant differences were noted for $\operatorname{DLP}\left(57.5 \pm 23.4 \mathrm{mGy} * \mathrm{~cm}\right.$ vs. $69.5 \pm 27.6 \mathrm{mGy}^{*} \mathrm{~cm}, P$ $=0.12$; Fig. $3 \mathrm{e})$ and for the calculated effective dose $(0.79$ $\pm 0.32 \mathrm{mSv}$ vs. $0.95 \pm 0.38 \mathrm{mSv}, P=0.12$; Fig. 3f). When CT examinations were standardized to a theoretical scan length of $5 \mathrm{~cm}$, hands-up position resulted in lower DLP and lower effective dose $(25.4 \pm 6.7 \mathrm{mGy} * \mathrm{~cm}$ vs. $33.6 \pm$ $9.2 \mathrm{mGy}^{*} \mathrm{~cm}, \mathrm{ED} 0.46 \pm 0.13 \mathrm{mSv}$ vs. $0.35 \pm 0.09 \mathrm{mSv}, P$ $=0.001)$.

Clavicular angle of both sides showed a moderate positive correlation with scan length (right: Spearman coefficient: $0.37, P=0.01$; left: Spearman coefficient: $0.37, P=0.01)$ and a moderate negative correlation with lateral diameter (right: Spearman coefficient: 0.597, $P<0.001$; left: Spearman coefficient: -0.62 , $P<0.001)$

\section{Discussion}

This work investigated the impact of arm position on depiction of the medial clavicular joint and related imaging parameters including noise as well as radiation dose in forensic clavicular CT examinations. To the best of our best knowledge, no literature has been published on optimal clavicular position in forensic CT examinations.

Several studies have shown that the arm position is relevant for image quality in CT examinations of different body parts. In concordance, we were able to demonstrate a lower image noise in CT examinations with arms up which was attributed to a reduced body diameter in this position. The finding is in line with several previous CT studies showing that upward arm positioning for thoracoabdominal and downward positioning of the shoulders for CT scans of the cervical spine enhance image quality $[7,10]$.

The aforementioned studies also demonstrated that with proper positioning, a reduction of radiation dose can be reached. Also, in our study, there was a tendency towards lower DLP and effective dose with hand position up which did not reach statistical significance. In fact, the longer scan range in the HU group counteracted the dose saving potentials. When corrected to a scan length of $5 \mathrm{~cm}$, the CTDI ${ }_{\mathrm{vol}}$, estimated effective dose, and the effective tube current time product were lower in subjects with elevated hands, which means that at the examined level, the applied dose was less.

Interestingly, we found a positive correlation between clavicular angle and scan length with a longer scan length in those subjects with hands placed upwards. This might be caused by the fact that sometimes, technicians were unsure about the relevant part of the clavicle. When the clavicle is placed horizontally in a small scan field, a major part of the clavicle can still be scanned. This is different in patients with a steep angle of the clavicle, where a longer and often not necessary scan field was applied. Optimal positioning and minimizing the scan length to the relevant part of the medial clavicular epiphysis seems crucial for further dose reduction. 
a

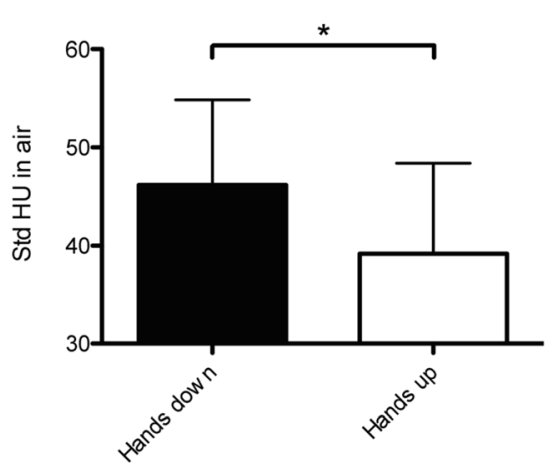

d

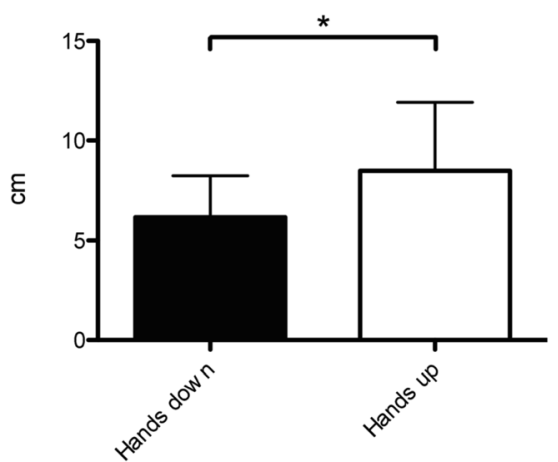

b

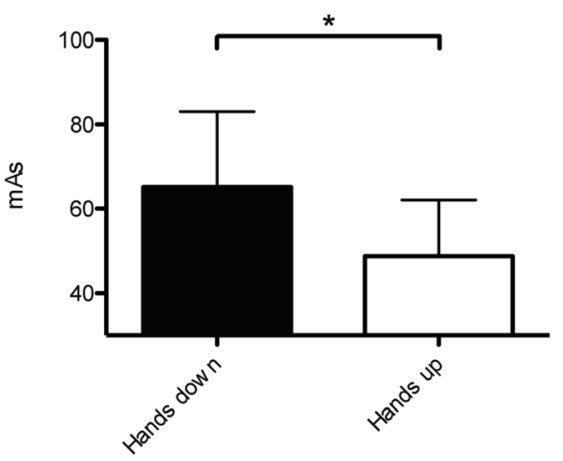

e

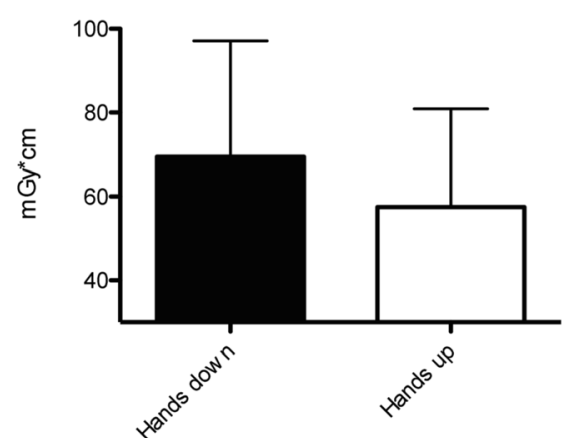

C

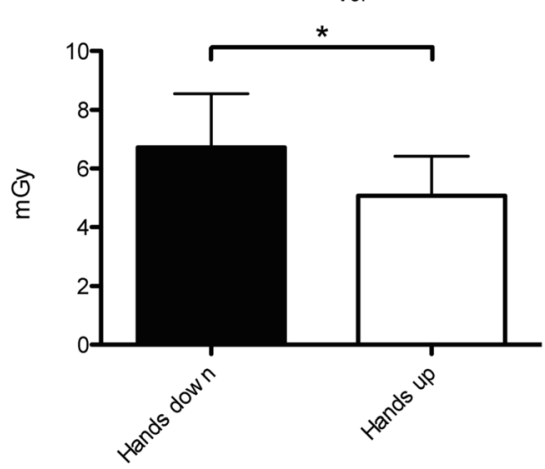

f

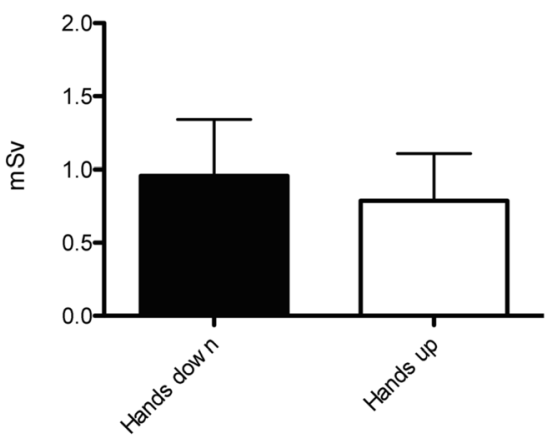

Fig. 3 Quantitative image noise (a) was evaluated at midlevel of the medial clavicular epiphysis on images reconstructed with iDose 4. Image noise was significantly higher in subjects with hands down than in subjects with hands up. And tube current time product (b) and $\mathrm{CTDI}_{\mathrm{vol}}$ (c) was higher in

Thus, technicians should be trained to position patients properly and to identify the relevant part of the clavicle.

We suggest the use of multiplanar reformations, in which axial views are aligned along the clavicular shaft in order to correct for changes of the clavicular position due to the elevated arms. MPRs are common practice when evaluating images that are acquired with multiple detector CTs [19]. This is especially important when imaging body parts that change their position according to the patient's body constitution or position in the scanner. Changes of reformation techniques have been reported to influence image quality [13] and viewing images in axial and coronal reformations are considered gold standard for the evaluation of the medial clavicular epiphysis in forensic age estimation [20-22]. While many important studies in the field forensic clavicular imaging have examined patients with hands positioned at the body [12], studies with retrospective analysis of the clavicle, especially those that use thoracic CT examinations, evaluated multiplanar reformations in patients with hands positioned upwards [23]. Furthermore, volume rendering techniques have been discussed for the evaluation of the medial clavicular epiphysis [24]. The adapted reformation of the clavicle and subjects with hands down. Scan length (d) was larger in subjects with hands up. DLP (e) and effective dose (f) showed no significant difference between the two groups. Data are presented as mean \pm standard deviation. Asterisks indicate significant differences $(P<0.05)$

possible also additional use of volume rendering techniques might facilitate the evaluation of the clavicle independent of the patient's position.

\section{Limitations}

Our study has several limitations. First, we only included 28 subjects with elevated arms, since those were the ones available during the included time period. Second, we only measured noise in the air. As described previously [16], this might not be representative of noise in bone.

\section{Conclusion}

Quantitative image noise in clavicular CT is less when the scan is acquired with an upward arm position. This might facilitate image analysis and open the door for further dose reduction in $\mathrm{CT}$ examinations of the medial clavicular epiphysis. 
Funding Open Access funding enabled and organized by Projekt DEAL.

Declarations This retrospective study was approved by the local ethics committee with waived informed consent due to the use of anonymized data.

Conflict of interest The authors declare that they have no conflict of interest.

Open Access This article is licensed under a Creative Commons Attribution 4.0 International License, which permits use, sharing, adaptation, distribution and reproduction in any medium or format, as long as you give appropriate credit to the original author(s) and the source, provide a link to the Creative Commons licence, and indicate if changes were made. The images or other third party material in this article are included in the article's Creative Commons licence, unless indicated otherwise in a credit line to the material. If material is not included in the article's Creative Commons licence and your intended use is not permitted by statutory regulation or exceeds the permitted use, you will need to obtain permission directly from the copyright holder. To view a copy of this licence, visit http://creativecommons.org/licenses/by/4.0/.

\section{References}

1. Schmeling A, Reisinger W, Geserick G, Olze A (2005) The current state of forensic age estimation of live subjects for the purpose of criminal prosecution. Forensic Sci Med Pathol 1(4):239-246. https://doi.org/10.1385/FSMP:1:4:239

2. AGFAD (2018) Stellungnahme: Forensische Altersdiagnostik bei unbegleiteten minderjährigen Flüchtlingen. Arbeitsgemeinschaft für Forensische Altersdiagnostik. https://www.dgrm.de/institute/ deutschland/institut-essen/news-essen/stellungnahme-forensischealtersdiagnostik-bei-unbegleiteten-minderjaehrigen-fluechtlingen/. Accessed 15.5.2020

3. Schmeling A, Grundmann C, Fuhrmann A, Kaatsch HJ, Knell B, Ramsthaler F, Reisinger W, Riepert T, Ritz-Timme S, Rosing FW, Rotzscher K, Geserick G (2008) Criteria for age estimation in living individuals. Int J Legal Med 122(6):457-460. https://doi.org/10. 1007/s00414-008-0254-2

4. Hermetet C, Saint-Martin P, Gambier A, Ribier L, Sautenet B, Rerolle C (2018) Forensic age estimation using computed tomography of the medial clavicular epiphysis: a systematic review. Int $\mathbf{J}$ Legal Med 132(5):1415-1425. https://doi.org/10.1007/s00414018-1847-Z

5. Schmeling A, Dettmeyer R, Rudolf E, Vieth V, Geserick G (2016) Forensic age estimation. Dtsch Arztebl Int 113(4):44-50. https:// doi.org/10.3238/arztebl.2016.0044

6. Kutanzi KR, Lumen A, Koturbash I, Miousse IR (2016) Pediatric exposures to ionizing radiation: carcinogenic considerations. Int $\mathrm{J}$ Environ Res Public Health 13(11). https://doi.org/10.3390/ ijerph13111057

7. Brink M, de Lange F, Oostveen LJ, Dekker HM, Kool DR, Deunk J, Edwards MJ, van Kuijk C, Kamman RL, Blickman JG (2008) Arm raising at exposure-controlled multidetector trauma $\mathrm{CT}$ of thoracoabdominal region: higher image quality, lower radiation dose. Radiology 249(2):661-670. https://doi.org/10.1148/radiol. 2492080169

8. Marsh RM, Silosky MS (2017) The effects of patient positioning when interpreting CT dose metrics: A phantom study. Med Phys 44(4):1514-1524. https://doi.org/10.1002/mp.12137
9. Euler A, Szücs-Farkas Z, Schindera S (2014) Möglichkeiten der Strahlenreduktion bei der CT des Körperstamms. Radiologie 14: 163-176. https://doi.org/10.1055/s-0034-1365687

10. Tozakidou M, Yang SR, Kovacs BK, Szücs-Farkas Z, Studler U, Schindera S, Hirschmann A (2019) Dose-optimized computed tomography of the cervical spine in patients with shoulder pull-down: is image quality comparable with a standard dose protocol in an emergency setting? Eur J Radiol 120:108655. https://doi.org/10. 1016/j.ejrad.2019.108655

11. Wittschieber D, Schulz R, Vieth V, Kuppers M, Bajanowski T, Ramsthaler F, Püschel K, Pfeiffer H, Schmidt S, Schmeling A (2014) The value of sub-stages and thin slices for the assessment of the medial clavicular epiphysis: a prospective multi-center CT study. Forensic Sci Med Pathol 10(2):163-169. https://doi.org/10. 1007/s12024-013-9511-x

12. Mühler M, Schulz R, Schmidt S, Schmeling A, Reisinger W (2006) The influence of slice thickness on assessment of clavicle ossification in forensic age diagnostics. Int J Legal Med 120(1):15-17. https://doi.org/10.1007/s00414-005-0010-9

13. Scharte P, Vieth V, Schulz R, Ramsthaler F, Püschel K, Bajanowski T, Pfeiffer H, Schmeling A, Schmidt S, Wittschieber D (2017) Comparison of imaging planes during CT-based evaluation of clavicular ossification: a multi-center study. Int J Legal Med 131(5): 1391-1397. https://doi.org/10.1007/s00414-017-1615-5

14. Rudolf E, Kramer J, Schmidt S, Vieth V, Winkler I, Schmeling A (2018) Intraindividual incongruences of medially ossifying clavicles in borderline adults as seen from thin-slice CT studies of 2595 male persons. Int J Legal Med 132(2):629-636. https://doi.org/10. 1007/s00414-017-1694-3

15. Wittschieber D, Schulz R, Vieth V, Kuppers M, Bajanowski T, Ramsthaler F, Püschel K, Pfeiffer H, Schmidt S, Schmeling A (2014) Influence of the examiner's qualification and sources of error during stage determination of the medial clavicular epiphysis by means of computed tomography. Int J Legal Med 128(1):183191. https://doi.org/10.1007/s00414-013-0932-6

16. Tozakidou M, Apine I, Petersen KU, Weinrich JM, Schindera S, Jopp-van Well E, Püschel K, Herrmann J (2019) Comparison of different iterative $\mathrm{CT}$ reconstruction techniques and filtered back projection for assessment of the medial clavicular epiphysis in forensic age estimation. Int J Legal Med 134:355-361. https://doi.org/ 10.1007/s00414-019-02214-X

17. Deak PD, Smal Y, Kalender WA (2010) Multisection CT protocols: sex- and age-specific conversion factors used to determine effective dose from dose-length product. Radiology 257(1):158-166. https:// doi.org/10.1148/radiol.10100047

18. Gervaise A, Osemont B, Lecocq S, Noel A, Micard E, Felblinger J, Blum A (2012) CT image quality improvement using adaptive iterative dose reduction with wide-volume acquisition on 320detector CT. Eur Radiol 22(2):295-301. https://doi.org/10.1007/ s00330-011-2271-7

19. Rydberg J, Buckwalter KA, Caldemeyer KS, Phillips MD, Conces DJ Jr, Aisen AM, Persohn SA, Kopecky KK (2000) Multisection $\mathrm{CT}$ : scanning techniques and clinical applications. Radiographics 20(6):1787-1806. https://doi.org/10.1148/radiographics.20.6. g00nv071787

20. Wittschieber D, Schulz R, Pfeiffer H, Schmeling A, Schmidt S (2017) Systematic procedure for identifying the five main ossification stages of the medial clavicular epiphysis using computed tomography: a practical proposal for forensic age diagnostics. Int $\mathrm{J}$ Legal Med 131(1):217-224. https://doi.org/10.1007/s00414-0161444-y

21. Kellinghaus M, Schulz R, Vieth V, Schmidt S, Schmeling A (2010) Forensic age estimation in living subjects based on the ossification status of the medial clavicular epiphysis as revealed by thin-slice multidetector computed tomography. Int J Legal Med 124(2):149_ 154. https://doi.org/10.1007/s00414-009-0398-8 
22. Rudolf E, Kramer J, Schmidt S, Vieth V, Winkler I, Schmeling A (2019) Anatomic shape variants of extremitas sternalis claviculae as collected from sternoclavicular thin-slice CT-studies of 2820 male borderline-adults. Int J Legal Med 133(5):1517-1528. https://doi. org/10.1007/s00414-019-02065-6

23. Gassenmaier S, Schaefer JF, Nikolaou K, Esser M, Tsiflikas I (2020) Forensic age estimation in living adolescents with CT imaging of the clavicula-impact of low-dose scanning on readers' confidence. 30(12):6645-6652. https://doi.org/10.1007/s00330-02007079-y
24. Rudolf E, Kramer J, Winkler I, Schmeling A (2019) Technical note: utilization of 3D-rendering for CT evaluation of extremitas sternalis claviculae within medical age assessment practice. Int J Legal Med 133(3):931-934. https://doi.org/10.1007/s00414-019-02025-0

Publisher's note Springer Nature remains neutral with regard to jurisdictional claims in published maps and institutional affiliations. 